\title{
Connotation of Historical Consciousness
}

\author{
Xue Yueai
}

Department of Social Sciences, Qiongtai Normal University, Haikou, Hainan 571100

Qtjg201506.

*Research on the Current Situation and Countermeasures of Higher Vocational College Students' Historical Consciousness in Ideological and Political Education in Hainan Province

Keywords: Historical consciousness; Consciousness of time and space change; Reflection on critical consciousness

\begin{abstract}
The connotation of historical consciousness is profound, and there is no consensus about it. Combined with the study of historical philosophy, historical consciousness contains consciousness of time and space change, causal consciousness and reflection on critical consciousness. Consciousness of time and space change is to observe and analyze historical figures and phenomena in specific time and space, and follow the rhythm of historical change and the pace to come to the reality, so that it has the ability to ductility to the future. Causation and awareness is that people dig the hidden causal link between subject and object, reveal various qualities from roots to rheology so as to explore the law of history and get close to the historical origin of thinking and ability in understanding history through complex and steady changes in the appearance. Reflections of critical consciousness shows as the reflection on the relationship between the conclusions people get in historical study and history reality, and the reflection on the relationship between history and reality.
\end{abstract}

\section{CLC number: G127～Document code: A Article number}

Historical consciousness belongs to the category of historical philosophy. Historical philosophy is a philosophical reflection on what history is and its derivative problems, and history is human thought, behavior trajectory, and in the final analysis, historical philosophy is the interpretation of human existence. In human complex and multi-level consciousness, historical consciousness is one of them, and it is the upper part with positive attribute. Because of its positive guidance to people and positive impact on society, historical consciousness is introduced into history education and has become an important training objective and object of inquiry. But historical consciousness is a concept with rich connotation and it is difficult to be explained. In Chinese and Western historical philosophy and theoretical research, scholars are trying to explain its essence and kernel which understandable and in place language. German scholar Johan Lusen put forward in "History and culture ---- on the status of history in life": "Historical consciousness first is the interpretation of time in a way of historical memories, and again recalls the narrative story in the form of memory effect."[1] Taiwan scholar Hu Changzhi argued that historical consciousness is "the state of mind that connects the phenomenon of life and some phenomena in the past."[2] Mr. Qu Lindong thought that historical consciousness is the experience and wisdom human beings gained in understanding their own history and study, and then apply them to guide the concept and requirements of a real life. [3] Scholars define the connotation of historical consciousness from the perspective of the relationship between ancient and modern and experience reflection, but the diversity of the concept itself makes this inquiry continue to advance and in-depth. The profound meaning of human consciousness is difficult to make a statement. The author believes that there must be consciousness of time and space change, causal consciousness and reflective consciousness in historical consciousness. 


\section{Consciousness of time and space change}

The subjects, events, phenomena and their correlations of historical disciplines are generated or occurred in specific time and space with their own time and space attributes. Space and time positioning is the basis of historical cognition. Man is the product of history and the creator and successor. Around persons, there is the occurrence of events and phenomena. Recognizing and studying people, in addition to natural attributes, their social attributes are based on a certain time and space network. In the vast universe, where do people come from, what do people do and how to affect others and the future? The answers to these questions need time and space coordinates. It is the memory and segmentation of time that when rolling in the long time forward, everyone has its own node in the time line, and it is because of clearance and division of the space, nations and countries form, and people have a group attribution and space orientation. Vertical and horizontal space-time staggering weaves out the coordinates of intersection of people. Then people, things and matter are in time and space. All disciplines are for people's study, so any discipline should take space and time as a guide. History is in time and space as a basis, so it has its unique discipline temperament. So history gives the first impression of vicissitudes.

To form historical consciousness in history education and learning, first have a sense of time and space change. It is the basic literacy of people's cognitive interpretation of history. Consciousness of time and space change is to observe and analyze historical figures and phenomena in specific time and space, and follow the rhythm and the pace of historical change to the reality, so that it has the ability to ductility to the future. It architectures the time sequence from past, today, and future, and in turn expands the field of vision to international and domestic space. It guides people out of the shackles of the present, leading the thinking between ancient and modern. In consciousness of time and space change, history is flowing and characters are fresh. It gives history flexibility. In history learning and research, the lack of awareness of time and space changes makes history chaos and fuzzy. The occurrence of all the phenomena is without evidence, which cannot be explained and it has no meaning. Therefore, primitive human, in order to sort out and remember the events, invented knot rope record, the principle of which is also marked in the order of time. Space and time consciousness is the urgent need in the early development of human consciousness, which is also the development of productive forces. The growing way of life makes the mind of this function develop in people. Then it is widely used in life and production. After the birth of history discipline, time and space consciousness is even a moment away. To play it vividly becomes a discipline and tradition. The consciousness of time and space is the basic criterion for defining things. Its foothold is still static. On this basis, it shows the internal relations of things in different time and space. Change is not only the embodiment of the dynamics of main thinking activities, but also the continuation of the object life through the activities of the subject. Time and space changes get together in order to enable people consciously and dynamically grasp, understand and explain the phenomenon in time and space of history, reality, and future. The enhancement of history change consciousness makes people avoid the fall into the pattern of kidnapping history and understand the history more objectively and rationally.

Consciousness of time and space change is in basic position of historical consciousness which shows that it is the primary consciousness of the historians. The construction of this consciousness is necessary and orderly.

\section{Causal contact consciousness}

Correlation view is the basic view of philosophy, and is one of the conclusions of mankind thinking on him and others, the world and the universe. Historical research also needs to explore the relationship between historical figures, people and events, phenomena and phenomena, and various ages. In essence, it is the relationship hidden behind historical phenomenon that builds a posture and momentum of vertical and horizontal history. So historical consciousness is essential and it has causal contact consciousness, which is full of its connotation and opens up the phenomenon behind the association. 
Historical phenomena are by no means isolated. Just as Marx's analysis of the nature of man, in reality, people are the sum of all social relations. Historical figures, the main history, are intertwined in the vertical and horizontal network. From family, clan to nation, country, and people are defined in multiple relationships. The ancients describe the complex social relations by five cardinal relationships. From history to reality, and then to the future, although people belong to a certain historical period, but historical figures connect ancient and future because of their ideas and achievements impact on society by travel beyond the shackles of time and space with invisible power. Today, Confucius thought is based on national nature, and becomes concern for the world because of its universal in human. British history philosopher Toynbee in the 1970s talk with Japanese historian Ikeda, said that to solve the twenty-first century social problems, only Confucius, Mencius and Mahayana Buddhism. [4] Any historical phenomenon occurs in a specific time and space, and what factors determine its appearance and empty? Why not in other periods, and will not wait as man's subjective desire to happen in the next period? The causal link behind historical phenomena, to a certain extent, restricts its process. Far since it has long been deeply rooted in history, the inevitable occurrence comes. For example, the occurrence of modern Chinese opium war, a big change in three thousand years, and the lead has long been buried in the 16th century's geography discovery and subsequent industrial revolution. Cut off the contact between Chinese and foreign, ancient and modern history and it is impossible to get close to historical truth.

Based on this, historical consciousness also must contain causal contact association, which is the depth existence of consciousness. Causal contact awareness is that people, in understanding history, try to figure out historical phenomena in different time and space, dig the hidden causal link in subject and object, reveal various qualities from roots to rheology, so as to explore the laws of history, and get close to historical minds thinking and ability. This awareness hybrids and deeply processes phenomena in different time and space. Contact is the latitude, and understanding is the longitude. It is deep rational understanding on the basis of perceptual knowledge. Historical research and educational teaching are all important. Emphasizing the background consciousness is the causal association of consciousness and application.

Cultivate historical sense of causation can train people's philosophical thinking and mine historical essence through historical appearance. It encourages people to consciously explore phenomenon accidental and the inevitability, relevance after event isolation. If you ignore the causal contact consciousness and blindly collect pieces of appearances, in the vast sea of history, you will see all fragments of history. Ancient and modern relations are separated, and people are always difficult to understand like voyage in the night without a compass. In learning history, we should gradually accumulate and consciously use historical causal link awareness, and people's ability to understand beyond passive acceptance stage and get into the level of initiative, consciously rational judgment, analysis, refining and clear sense of transparency. Of course, the use of this awareness must be based on objective, real historical data. Under the guidance of historical materialism, use scientific way to think and explore. Otherwise, free contact of reality from history and the principles can only fall into the quagmire of imagination, suspicion of subjectivism, which is not only of no benefit for history, but also misleading themselves and others.

\section{Reflection and critical consciousness}

"Critical historical philosophy" and "criticism of historical philosophy" are the mainstream of western historical philosophy. People's reflection of historical process is an important way to promote the exploration of historical knowledge. History is the reflection of the combination of subject and object after the exploration, reflection and criticism of historical phenomena. If there is no reflection on critical consciousness, what is the ultimate destination of historical study? Human history is an objective existence, development and evolution. People's reflection and criticism on history is the cognition, understanding and interpretation of the subject on the object. People come from history with a deep historical imprint, and people jump out of history, observe and reflect the history, and promote the historical process. Therefore, historical consciousness contains people's sense in history. People learn, study history, and learn from them, find the law, explore the wisdom, 
and sublimate emotion. These experiences accumulation is used for heritage. Historical consciousness is also people's consciousness in history, and people are in the course of history, looking back on their own history, and live a far-sighted future. Living in reality, man should hold emotion and reason, thought and practice to inherit history, face reality and create the future. Therefore, historical reflection and critical consciousness is the advanced stage of historical consciousness and an inevitable sublimation.

Reflection and critical consciousness shows in people's historical knowledge learning and historical causal relationship research. History is the study of original, traces and laws. Its research results can only be close to history, and not the same as the reality of history. It is precisely because mankind can only be on the way to the truth; this discipline is given infinite charm. But this does not mean that its rationality and scientificity should be questioned. Even if we are the parties in this history, it is difficult to see with their own eyes and exhaust an era. The reality is complex and changeable, creating confusing, mysterious and unpredictable history. People, in history research and interpretation, often restore and describe the history with their own practical experience subjectively, whether for historical books or historical exposition. This process itself contains the critique of historians. Predecessors of the study had insight and wisdom of crystallization, and if history readers have no reflection on critical consciousness, they can only get mechanical memory and passive acceptance, while losing their own reflection and judgment, and the true meaning of history is submerged. Therefore, reflection and critical consciousness to a certain extent is critical of criticism, and self-reflection on the basis of others reflects. Every academic historian unconsciously experiences in the process, but unconsciousness is not enough. The construction of historical reflection critical consciousness is to develop from unconscious state to conscious initiative stage.

Reflection and critical consciousness also includes the reflection on the relationship between history and reality. The function of history has been repeatedly discussed since ancient times. It is the inseparable relationship of reality and the future that makes this ancient discipline glow new look. History is man's memory and cognition of himself, clan, and the world. Without history, there is no reality. People always get reality by reflection on history and get to future by criticizing reality. Reflection and critical consciousness is an important way to make history move from theory to practice. Reflection and critical consciousness builds a bridge of history and reality. History limited to the history is no vitality. The confined knowledge of historical knowledge cannot get the essence of history, as well as reflection and criticism lacking understanding. The reflection and critical consciousness on history is not only to get to the truth of history, but also to make people not limited to this, and further consider the true meaning of history. Find the meaning of life in the past, present, and future.

If the above three layers of content are given comprehensive analysis, space-time change consciousness, causal contact consciousness, reflection and critical consciousness are rarely exist, which are often interacted and interlocked. Historical phenomenon in time and space change is in historical causal relationship with historical inevitability and contingencies. We find historical laws and narrow the distance between history and reality. In the analysis of historical figures, Xi Jinping pointed out: "The evaluation of historical figures should be placed in his time and social historical conditions and cannot be without scientific grasp and comprehensive understanding of historical conditions, historical process and historical laws. We cannot ignore the relationship between historical inevitability and historical contingency. "[5] This is the role of historical consciousness in the play. After a long period of cultivation and cultivation, historical consciousness gradually internalizes into people's way of thinking and attitude, and imperceptibly guides theory understanding and practical use. How to construct historical consciousness is a more complicated problem on the basis of connotation discussion, which needs further study.

The connotation of historical consciousness is broad and profound, and it is difficult to make a definition that makes all parties convinced. We are not to arbitrarily define what historical consciousness is and think about what is essential to historical consciousness. The above-mentioned historical sense of time and space change, causal consciousness, reflection and critical consciousness cannot summarize the whole picture and profound meaning of historical 
consciousness, but provide the opportunity that leads to deep thinking and discussion.

\section{References}

[1] Johan Lusen. History and Culture ---- The Status of History in Life [J]. Shandong Social Sciences, 2005: 4.

[2] Hu Changzhi. Historical consciousness and social change [M]. Taipei: Lianjing Publishing Company, 1988: 145.

[3] Qu Lindong. History, reality, life----Meditation on history [M]. Hangzhou: Zhejiang People's Publishing House, 1994: 6.

[4] Toynbee, Ikeda. Looking forward to the 21st century ---- Toynbee and Ikeda dialogue: Hong Kong: International Culture Press, 1999: 289.

[5] Xi Jinping. Xi Jinping's speech in commemoration of Comrade Mao Zedong's 120th anniversary [N]. People's Daily, 2013-12-26. 